\title{
Domestic adjustment costs, interdependence and dissent in the Council of the European Union
}

\author{
JAVIER ARREGUI ${ }^{1} \&$ ROBERT THOMSON ${ }^{2}$ \\ ${ }^{1}$ Department of Political and Social Science, Universitat Pompeu Fabra, Spain; ${ }^{2}$ School of Government and \\ Public Policy, University of Strathclyde, UK
}

\begin{abstract}
Liberal international relations theory posits that the behaviour of states is affected both by domestic interests and other states with which they are linked in significant patterns of interdependence. This article examines the relevance of this proposition to states' behaviour in the most powerful institution in the furthest reaching example of regional integration in the world today: the Council of the European Union. Compared to previous research, more detailed evidence is analysed in this article on the substance of the political debates that preceded Council votes. It is found that states' disagreement with both discretionary and nondiscretionary decision outcomes affects the likelihood that they dissent at the voting stage. Moreover, in line with the theory posited here, the behaviour of states' significant trading partners has a particularly marked effect on the likelihood that they will dissent.
\end{abstract}

Keywords: Council of the European Union; voting behaviour; legislative decision making; discretion; domestic interests; interdependence

\section{Introduction}

After the European Union's Member States negotiate on legislative proposals, they have the opportunity to vote in the Council of the EU. States' behaviour at the voting stage provides an excellent research opportunity to refine and test two central propositions of liberal international relations theory (Moravcsik 1997). The first is that states' behaviour is to a large extent determined by their preferences. The second is that their behaviour is also affected by significant patterns of interdependence. Developing and testing these propositions in the context of voting in the Council requires a more detailed analysis of the contents of legislative proposals than offered in most existing studies of this topic (Mattila 2004, 2008, 2009; Hayes-Renshaw et al. 2006; Hagemann 2008; Hosli et al. 2011; Plechanovová 2011). The important research that has been published in this journal and elsewhere typically examines large numbers of votes, usually several hundreds or even thousands, and explores general patterns in states' behaviour - for instance, by identifying which states generally vote in similar ways. Our study complements this existing research by developing theoretical propositions that include states' policy positions on the proposals on which they vote and testing these propositions with more detailed information than has previously been available.

Existing research indicates that dissent is a rare event. In one of the most recent studies, Hosli et al. (2011) examined 1,358 acts that were voted on in the period from May 2004 to December 2006 when the EU consisted of 25 Member States. This gives a massive 33,950 observations in which a Member State could have dissented. The researchers identified 
dissent in the form of voting against, abstaining or entering statements in the Council minutes in only 432 of these cases, which amounts to only 1.3 per cent of the observations. This finding fits well with depictions of the Council as a place where actors adhere to the norm of consensus (Heisenberg 2005; Lewis 2008). However, it sits uncomfortably with research that reveals the presence of considerable disagreement among Member States on legislative proposals (Arregui 2008; Thomson 2011: Chapter 3). A trivial explanation of the different findings may be that these studies focus on different sets of cases, but we show that this is not the reason.

The following section sets out our conception of dissent at the voting stage and our proposed explanation of this phenomenon. Our explanation is relevant to proposals that raise at least some controversy. We then describe our research design, which includes the most detailed dataset currently available on specific controversies raised by legislative proposals: the DEUII dataset (Thomson et al. 2006, 2012). The research design section also describes how we operationalise the key independent and dependent variables in our study. The final sections present the analyses and conclusions.

\section{Dissent at the voting stage: Conceptualisation and explanation}

Dissent is a clear display of disagreement by a state with the contents of a proposal at the voting stage. Dissent in this context is public behaviour - not clandestine opposition. It consists of voting against, abstaining or placing a statement that conveys disagreement with at least one aspect of the proposal without necessarily voting against or abstaining. Hagemann (2008) was, to our knowledge, the first researcher to investigate statements by Member States in Council minutes in addition to abstaining or voting. Placing statements is an important behaviour to include when studying how often and why dissent occurs since it serves the same function as voting against or abstaining. Moreover, Member States insert statements that register their disagreement without formally voting against or abstaining. Not all statements clearly signal Member States' disagreement with the contents of proposals, but instead clarify a Member State's interpretation of the proposal in question. Such clarifying statements do not fall under our definition of dissent.

Hosli et al. (2011) suggest that entering statements, abstaining and voting against form an ordered scale of increasing levels of opposition to a proposal. We disagree that there is a clear ascending order in the level of opposition, and instead treat these behaviours as equivalent. A strongly worded statement may serve as a stronger signal of opposition than a vote against or abstention. Furthermore, when the qualified majority voting rule applies in the Council, voting against and abstaining are equivalent in that the proposal needs to receive the support of Member States that together meet the threshold. By contrast, when the unanimity rule applies, only voting against can block the passage of a proposal since abstentions do not count as 'no' votes. Our main theoretical interest lies in explaining dissent - not the particular form it takes. A secondary consideration is that given the rarity of dissent, there are too few observations with which to identify the causes of each of the three forms of dissent with a sufficient degree of confidence.

When explaining the occurrence of dissent at the voting stage, our point of departure is that the policy positions expressed by Member States in the preceding negotiations reflect 
their underlying policy preferences, and that the differences between these preferences and the outcomes of the negotiations affect whether they dissent. Member States' policy preferences are defined to a large extent by their national economic and political attributes. This is one of the core propositions of liberal international relations theory: in particular the proposition that:'States ... represent some subset of domestic society, on the basis of whose interests state officials define state preferences and act purposefully in world politics ... [and that] what states want is the primary determinant of what they do' (Moravcsik 1997: 518, 521). Similarly, Achen (2006: 121) suggests that states' preferences are readily observable in their policy positions: "An actor's "most preferred point" is a clear idea and relatively easy to measure.'

Governments generally prefer to avoid the adjustment costs involved in changing existing policies. These adjustment costs include investments in new policies and procedures to bring about policy change, as well as the effects of political opposition to change. Groups with interests in existing policies often voice opposition to change, and governments generally find it far more difficult to enact policy changes than to accept the policies inherited from previous governments (Rose \& Davies 1994). Consequently, when staking out policy positions in EU negotiations, state officials often advocate the uploading of their national arrangements to the European level (Börzel 2002). An official from a permanent representation of a Member State in Brussels described the way in which states typically formulate their positions during negotiations: '[M]ember States often try to give their national laws as a "gift" to the rest of Europe by arguing that everyone should do it their way. ${ }^{1}$ Similarly, a case study of the EU's air pollution regime illustrates how Germany and the United Kingdom attempted to fashion EU regulations in line with their existing national arrangements (Héritier 1995: 278-279).

Our overarching expectation is that Member States are more likely to dissent from a proposal, the more they disagree with the outcomes contained in it. The mechanism behind this effect is that governments seek to avoid negative effects on their domestic levels of support from political opposition by groups with entrenched interests in the status quo. By dissenting at the voting stage, governments signal to these groups that they are not the ones responsible for the policy changes being introduced. According to this mechanism, dissent at the voting stage is not an attempt to avoid the material costs involved in implementing policy change, such as setting up new national agencies to implement an initiative or restructuring bureaucracies. By the time a proposal is at the stage of being formally adopted in the Council, either by a formal vote or simply by being agreed, it is invariably clear that the proposal has sufficient support to pass. Therefore, dissenting behaviour cannot be an attempt to avoid such material costs. Because decision making in the Council is far from transparent, such publicly registered verifications of dissent are relevant to governments that wish to make domestic groups aware of their opposition to the proposals.

We expect the effect of disagreement to be weaker, although still present, when the outcomes with which states disagree give them discretion. Laws often contain discretionary provisions (Epstein \& O'Halloran 1999; Franchino 2007; Thomson \& Torenvlied 2011). We conceive of discretionary provisions broadly, as outcomes that grant discretionary power to Member States during the implementation stage or that exclude contentious provisions altogether. Discretionary outcomes allow states to keep their existing arrangements to at least some extent. Such flexibility allows Member States to avoid or reduce domestic 
adjustment costs. In this way, discretion weakens the impact of Member States' disagreement with decision outcomes on their propensity to dissent. The effect of disagreement is unlikely to be eliminated entirely because discretionary outcomes often specify some limits or conditions to which Member States must adhere within a range of policy options.

Our expectation that states' disagreement with outcomes increases the likelihood they will dissent contrasts with Novak's (2013: 1100) view on 'silence as a means of avoiding blame'. According to Novak's research, which is based on interviews with practitioners, Member States remain silent at the voting stage, even when decision outcomes deviate from their preferences, so that domestic interests' attention is not drawn to the fact that their national governments lost. We acknowledge that many practitioners hold this view, but do not find it plausible that domestic interests are oblivious to legislative proposals that affect their interests even moderately. Domestic interests are aware of the fact that Brussels is an increasingly important source of regulation, and they monitor EU developments closely. The analyses presented here allow our argument that 'voice is a means of avoiding blame' to be tested against the alternative argument that 'silence is a means of avoiding blame'.

Our expectation on the effect of disagreement on dissent is similar to that of Høyland and Wøien Hansen (2014) in their recent study of Council voting, which examines some of the same legislative proposals and data on states' policy preferences that we use. Their sophisticated study confirms that the possible linkage between states' policy preferences and voting behaviour is relevant to the field. However, our studies differ in numerous ways. Most importantly, our theoretical concern is with the effects of domestic adjustment costs, discretion and, as detailed below, interdependence, while Høyland and Wøien Hansen do not consider these factors. Moreover, their study focuses on 46 of the 118 legislative proposals included in our analysis. ${ }^{3}$

Another core assumption of liberal international relations theory leads us to expect that a Member State's decision on whether to dissent is affected by other Member States. '[T]he expected behavior of any single state ... reflect[s] not simply its own preferences, but the configuration of preferences of all states linked by patterns of significant policy interdependence' (Moravcsik 1997: 523). While all EU Member States are linked to each other in 'patterns of significant policy interdependence', some are more strongly linked than others. Interdependence theorists often refer to trade relations (Keohane \& Nye 2011). We also use trade between Member States as a measure of interdependence, and this measure differs markedly between different pairs or 'dyads' of EU states. Similarly, Naurin and Lindahl's (2010) research on cooperation relations among Member States' permanent representations in the Council finds different levels of cooperation. Not only do neighbouring states tend to trade more, they also tend to cooperate more in forming common positions. For instance, the Nordic states tend to cooperate more with one another than with other states, as do the Visegrad states and to some extent the southern states. For our analysis, the trade measure is preferable to Naurin and Lindhal's measure since the latter is based on key informants' judgements and may not be exogenous to states' voting behaviour.

We expect any given state to be influenced by the behaviour of other states, particularly those with which it has strong interdependencies. Although states' voting behaviour occurs simultaneously at the voting stage, Member States that object so strongly to a proposal that they intend to dissent in some way at the voting stage usually make that clear earlier in the 
negotiations. This means that their behaviour, or at least intended behaviour, has the possibility of affecting other states' behaviour.

There are several reasons why states' propensity to dissent could be affected by the dissenting behaviour of other states, particularly those with which they have strong interdependencies. Interdependence theorists highlight the importance of the multiple channels of contact between governmental and nongovernmental actors in interdependent states (Keohane \& Nye 2011:21). These multiple contacts, which are pervasive in the Council of the EU, mean that state representatives are influenced not only by their own domestic interests, but also by representatives of other states. Issue linkages, whereby states connect their behaviour on one issue to other states' behaviour on other issues, are another salient consequence of interdependence (Keohane \& Nye 2011: 25-6). Issue linkages may also cause states' behaviour at the voting stage to be affected by other states' behaviour. According to this mechanism, when states dissent as a consequence of another state's dissent, they are signalling that they are reliable partners. This requires a degree of reciprocity, whereby states dissent in support of other states in anticipation of support from those other states in the future. A distinct, though not contradictory, mechanism refers to the social costs of dissent. Novak $(2013: 1102)$ refers to the social pressure of groupthink in perpetuating silence in the Council at the voting stage. When cohesive group behaviour breaks down, even with just one state breaking the code of silence, the social costs of norm violation fall, which makes other states more likely to dissent.

We summarise our theoretical expectations in the following two hypotheses:

H1: A Member State is more likely to signal dissent from a proposal, the more it disagrees with outcomes in the proposal, particularly with outcomes that give it little discretion during the implementation stage.

H2: A Member State is more likely to signal dissent from a proposal, the more other Member States signal dissent from the proposal, particularly other Member States with which it is linked in strong patterns of interdependence.

\section{Research design}

The analyses are performed using the DEUII dataset (Thomson et al. 2006, 2012). We use 118 legislative proposals from this dataset on which we have gathered data on Member States' behaviour at the voting stage. Voting data are only available for proposals that were adopted. So our study is limited in the same way as previous studies in this respect. These legislative proposals were selected for raising at least a minimum level of controversy. Unlike previous studies of voting in the Council, we do not attempt to study Member States' behaviour in the population of votes (Mattila 2004, 2008, 2009; Hayes-Renshaw et al. 2006; Hagemann 2008; Hosli et al. 2011; Plechanovová 2011). Instead, our main interest lies in states' behaviour in relation to proposals that are at least somewhat controversial, and in testing our theoretical expectations.

Nonetheless, our theoretical propositions and empirical analyses are relevant to states' behaviour on legislative proposals that would not be considered controversial enough for 
inclusion in the DEU dataset. Validity tests of key informants' reports on issues in this dataset revealed that informants generally do not report issues that are of relevance to only one or two Member States (Thomson et al. 2006: 330-341). This means that states may disagree with outcomes in EU laws that were not controversial enough to include in our selection. In addition, our study contains the full possible range of variation on the explanatory variables referring to each Member State's disagreement with outcomes, since we have many observations in which Member States agreed entirely with the contents of the proposals that were adopted. This broadens the relevance of our study to legislative proposals that are uncontroversial.

Legislative proposals were selected according to three criteria: the time period, the type of legislative procedure and the level of political importance. Regarding the time period, legislative proposals were included if they were on the Council's agenda in the years 1999 and/or 2000, or were discussed for the first time in the Council after the 2004 enlargement. Legislative proposals introduced up to June 2008 were included in the post-2004 study. Concerning the decision-making procedure, the selected legislative proposals were subject to either the consultation or the codecision (now the ordinary) legislative procedures - the two most commonly used procedures. There is also variation in the Council voting rule, qualified majority voting (QMV) or unanimity, for which we control in the following analyses. Regarding political importance, the selection was restricted to proposals on which there was an indication of at least some political importance and controversy evident in media reports and interviews with key informants. The policy areas represented most prominently in the selection are agriculture, internal market, justice and home affairs, and fisheries, but many other policy areas are present too.

Information on controversial issues and actors' initial positions on these issues was collected in 349 semi-structured interviews with key informants. These interviews typically lasted between 60 and 90 minutes. The key informants were selected for their knowledge of the detail of the dossiers under investigation. Individuals with different institutional affiliations were interviewed. The 47 Commission officials interviewed were responsible for drafting the proposals and/or monitoring the subsequent discussions. The 236 officials from the permanent representations were the responsible desk officers. The 45 individuals from the EP were either MEPs or their assistants. A further nine interviewees worked in the Council secretariat and 12 in interest groups. During the course of these semistructured interviews, key informants were asked to describe the controversial issues to the interviewers and these controversies were reconstructed as policy scales ranging from 0 to 100 . For each controversial issue, key informants were asked to indicate the policy alternative initially favoured by each stakeholder after the introduction of the proposal and before the Council formulated its common position'. They were also asked to estimate the level of salience each actor attached to each controversial issue. Again, salience was estimated on a scale from 0 to 100. These salience estimates were divided by 100 in the analyses below. More details of the selection criteria, data-collection procedures and reliability tests are contained in the relevant publications of the DEU project (Thomson et al. 2006, 2012).

Table 1 gives an example of one of the legislative proposals included in the present study. The table refers to two of the controversial issues raised by the legislative proposal on emission allowances in the aviation sector. The Commission introduced this proposal in 
Table 1. The two main controversies raised by the proposed directive on emission allowances in the aviation sector

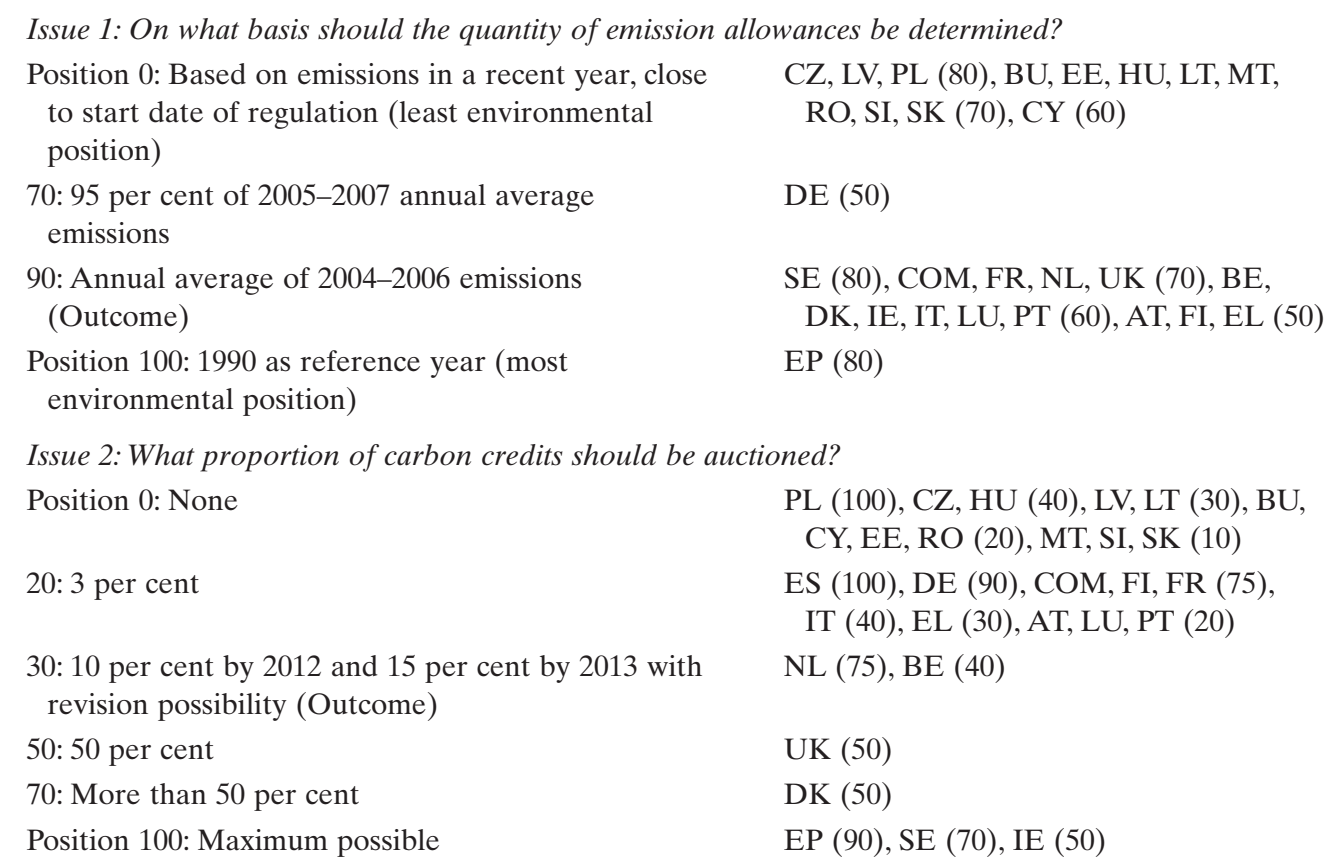

Note: Salience scores for preceding actors in parentheses. Proposal COD/2006/304. AT: Austria; BE: Belgium; BU: Bulgaria; CY: Cyprus; CZ: Czech Republic; DK: Denmark; EE: Estonia; FI: Finland; FR: France; DE: Germany; EL: Greece; HU: Hungary; IE: Ireland; IT: Italy; LV: Latvia; LT: Lithuania; LU: Luxembourg; MT: Malta; NL: The Netherlands; PL: Poland; PT: Portugal; RO: Romania; SI: Slovenia; SK: Slovakia; ES: Spain; SE: Sweden; UK: United Kingdom; COM: Commission; EP: European Parliament.

December 2006. Despite extensive consultations prior to the introduction of the proposal, it raised considerable controversy among the Member States. This legislative proposal sought to address climate change by including the aviation sector in the EU's emissions trading scheme. The first controversial issue concerned the calculation of the quantity of pollution allowances that should be given to the airline industry. On one side of this debate were the actors that favoured a relatively low quantity of allowances, which would drive up the cost of polluting; these actors consisted of the Commission, EP and old EU-15 Member States, although there were some differences within this latter group. These actors are placed at or close to position 100 of the policy scale representing this issue. On the other side of the debate were the 12 new Member States; these actors promoted a relatively high quantity of allowances, which would permit the aviation industry to pollute more (position $0)$. The outcome was in line with the Commission's initial legislative proposal in this respect (position 90).

The second controversy concerned the auctioning of carbon credits; the issue was about what proportion of these credits the aviation industry should be allowed to auction. Again, the new Member States took the same position, which was that there should be no auctioning. They argued that this would impose unacceptable costs on the aviation industry. The other actors favoured auctioning, but to different degrees. The Commission and most 
old Member States took the position that a small proportion of the credits should be auctioned. The EP together with Ireland and Sweden took the most radical position, arguing that the industry should be allowed to auction a far larger amount of credits. The EP's first opinion stated that 25 per cent of credits should be auctioned in 2011 and that this percentage should be increased to the level in other sectors in subsequent years. The outcome on this second issue involved a revision of the initial legislative proposal to bring it somewhat closer to the EP's proposed amendment. The outcome brought the percentage of credits to be auctioned up to 10 per cent by 2012 and 15 per cent by 2013 with the possibility of revision. Key informants placed this outcome at position 30 on the policy scale.

Since this proposal was subject to the codecision procedure, it is unsurprising that the outcomes bear the mark of the European Parliament (EP). Given that the EP has more power under the codecision procedure than under the consultation procedure, states with positions closer to the EP generally agree more with decision outcomes and therefore have less policy-based incentives to dissent when codecision applies. We do not, however, include the legislative procedure as a control variable since in this analysis we are interested in the effect of states' disagreement with outcomes on dissent, rather than explaining variation in states' disagreement with outcomes.

The outcomes contained in the emissions case do not give any discretion to Member States with respect to the controversies identified in Table 1. The outcome on each of the specific controversies included in the dataset was examined to determine whether it gave discretion to Member States during the implementation stage either by specifying a range of policy alternatives from which a state could choose and still comply with the law, or by limiting the scope of the proposal to exclude the contentious item from the proposed law at least in part. Although the emissions case does not contain discretionary outcomes, these were fairly common occurrences: a total of 73 out of 317 issues coded in the entire dataset ( 23 per cent) had decision outcomes that were discretionary. $^{2}$

Since the outcomes in the emissions case were non-discretionary, we would expect Member States that disagreed with these outcomes to signal their dissent at the voting stage. To some extent, the evidence supports this proposition. Malta and Cyprus, both of which were quite far from the decision outcome on the first main controversy, entered statements into the Council minutes when a vote was taken on 24 October 2008. The statement by Cyprus includes the following text: 'Cyprus would like to place on record its serious concerns regarding the adverse effects expected to be caused by the implementation of the proposed Directive on including aviation activities in the ETS within the EU', and went on to detail these concerns. Malta voiced similar concerns in its statement. A few other statements were also entered into the minutes that indicate dissent from the contents of the proposal. ${ }^{4}$

Testing our theoretical propositions requires a measure of Member States' disagreement with nondiscretionary and discretionary outcomes. In the following analyses we measure a state's disagreement with nondiscretionary outcomes as the sum of the salience weighted absolute distances between that state's policy positions and the nondiscretionary outcomes contained in a proposal. For ease of interpretation in the analyses, this number is divided by 100 . As a formula: 


$$
\text { disagreement }_{i}=\frac{\sum_{a=1}^{n} \text { salience }_{\text {ia }} \mid \text { position }_{\text {ia }}-\text { outcome }_{a} \mid}{100}
$$

where disagreement $_{i}$ is the level of actor $i$ 's disagreement with the non-discretionary outcomes in a proposal; $a$ is the first issue in a set of $n$ issues in a proposal that have non-discretionary outcomes; salience $_{i a}$ is the level of salience actor $i$ attaches to issue $a$; position $_{i a}$ is the policy position of actor $i$ on issue $a$; and outcome $_{a}$ is the (non-discretionary) decision outcome on issue $a$.

We apply the same formula to the discretionary outcomes in a proposal to obtain a measure of Member States' disagreement with discretionary outcomes. The only difference is that we add the weighted distances over the issues with discretionary outcomes. Note that these policy distances are weighted by salience, which we transform to range from 0 to 1 . Salience-weighted distances have been used in previous studies as measures of actors' utility losses (e.g., Bueno de Mesquita 1994: 79-82). Member States that are indifferent (i.e., do not have a policy position on a controversial issue) have a salience value of 0 , and therefore a value of 0 on this disagreement measure.

These measures of disagreement involve comparisons of distances across different policy scales that refer to substantively different topics. These distances are comparable in the sense that the endpoints of each policy scale map out the range of policy alternatives considered by the actors. Although we consider such comparisons appropriate, we run a robustness test with dichotomous measures of these distance variables, which simply measure whether or not Member States agreed with all of the nondiscretionary and discretionary outcomes in a proposal, and obtain essentially the same results. Using dichotomous measures of disagreement means that we do not compare the distances across issues, or include states' salience scores, but only include information on whether or not the state's policy positions deviated from at least one of the discretionary or nondiscretionary outcomes in the proposal.

Our second hypothesis requires that we measure the levels of interdependence between each pair of Member States. We follow previous research on interdependence and construct a measure based on trade flows between each pair of Member States. We take the value of imports and exports between Member States $i$ and $j$ as a percentage of Member State $i$ 's GDP as our measure of $i$ 's dependence on $j$. We take the average of this measure over the years 2000-2005 and 2006-2010, using Eurostat data, and link these measures to votes taken in each period. The average trade between each ordered dyad of states as a percentage of the first state in the dyad's gross domestic product (GDP) was 3.56 per cent in the years 2000-2005 and 2.31 per cent in the years 2006-2010. In the first period, 110 of the 210 ordered dyads of the 15 Member States had above average trade. In the second period, 185 of the 702 ordered dyads of the then 27 Member States had above average trade. The strongest trading dyad in the second period consisted of the Czech Republic and Germany, whereby trade amounted to 36.98 per cent of the Czech Republic's GDP. As a percentage of Germany's GDP, this trade amounted to only 2.25 per cent. Our measure therefore reflects the fact that dependence is asymmetric. In this case, Czech representatives are more influenced by the behaviour of German representatives than vice versa. By comparison, 
trade between the Netherlands and Belgium amounts to high percentages of both countries' GDPs: 15.50 and 25.05 per cent, respectively. Consequently, for these interdependent states we expect both Dutch and Belgian representatives' behaviour to influence each other. For each Member State in relation to each legislative proposal, we identify the number of other states with which it had above average trade and that dissented at the voting stage. We also identify the number of other states with which it had an average or less than average trade and that dissented.

\section{Analysis}

Figures 1 and 2 give the frequencies of different types of dissent by each Member State. Figure 1 refers to the 65 selected legislative proposals from before the 2004 enlargement, while Figure 2 refers to the 53 selected proposals from after 2004. The main descriptive finding is that dissent at the voting stage is a rare event, even in this sample of relatively controversial legislative proposals. The height of each bar represents the number of cases in which the Member State in question voted against, abstained or entered a statement in the minutes reflecting its dissent from the outcome without either voting against or abstaining. These are small frequencies compared to the numbers of proposals in our sample. The highest number of dissents was found for Ireland in the post-2004 period (Figure 2); Ireland signalled its disagreement at the voting stage on five of the 53 proposals in this period, which is still only 9.4 per cent. By contrast, Ireland and two other Member States (Finland and Italy) dissented from none of the proposals voted on prior to the 2004 enlargement (Figure 1). If we consider each of the 118 legislative proposals in relation to each of the 15,25 or 27 states that were EU members at the time each proposal was subject to a vote in the Council, there are 2,384 observations. In only 85 of these 2,384 observations did we find dissent of any kind, which amounts to only 3.6 per cent. The small percentage of

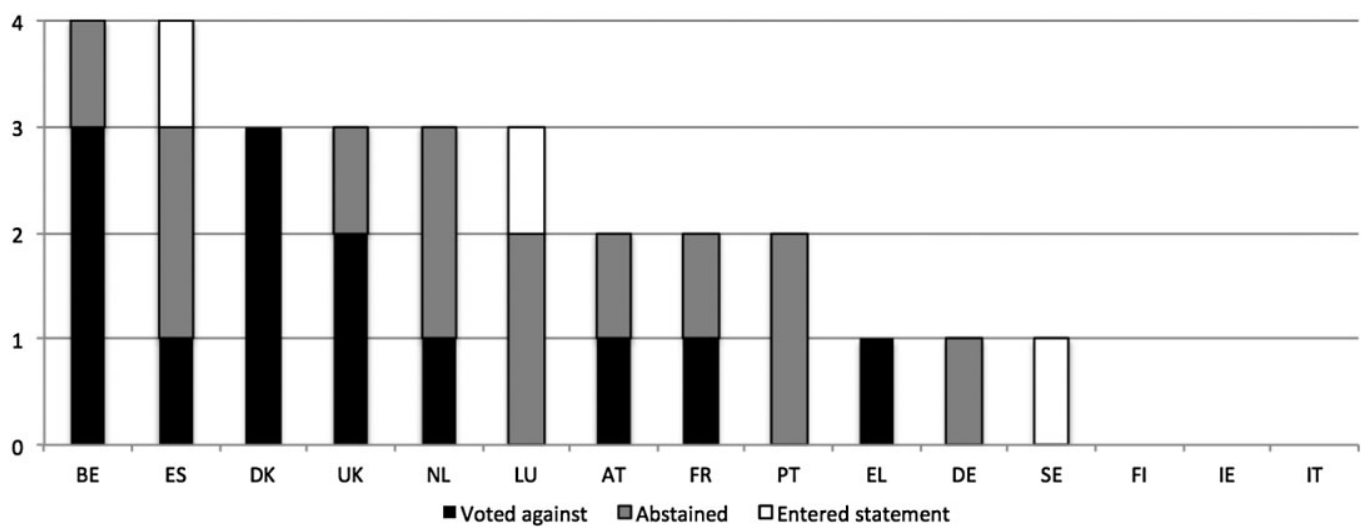

Figure 1. Frequency of dissent before the 2004 enlargement on selected proposals.

Note: Member States' behaviour regarding 65 legislative proposals voted on before the 2004 enlargement Source: Legislative proposals from the DEUII dataset. 


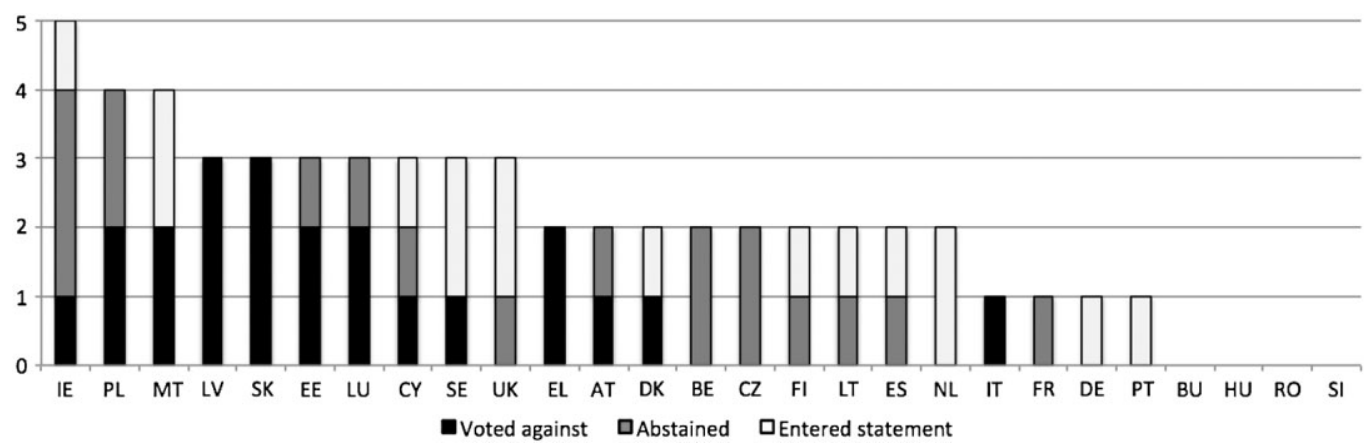

Figure 2. Frequency of dissent after the 2004 enlargement on selected proposals.

Note: Member States' behaviour regarding 53 legislative proposals voted on after the 2004 enlargement. Source: Legislative proposals from the DEUII dataset.

observations with positive values of dissent means that rare-events logistic regression is an appropriate technique for analysing these data since standard logistic regression could yield biased estimates of the effects (King \& Zeng, 2001). ${ }^{5}$

Table 2 includes descriptive information on the independent variables included in the analyses. The independent variables are not highly correlated. The two variables referring to other Member States' dissenting behaviour, for above and below average trading partners, are not highly correlated $(\mathrm{r}=0.33)$. We therefore include all relevant variables in the same model.

Model 1 in Table 3 gives the results of our main model. The exponents of the coefficients are shown, which are interpreted as effects on odds ratios. This means that values above one indicate that the relevant explanatory variable has a positive effect on the odds that Member States dissent, while values less than one indicate a negative effect. In line with the first hypothesis, Member States' disagreement with nondiscretionary decision outcomes increases the odds they will dissent at the voting stage. The exponentiated coefficient of 2.69 means that as our measure of disagreement with nondiscretionary outcomes increases by one unit, the odds of dissent more than double. While this is a substantively important effect, given the rarity of dissent, this translates into probabilities of dissent that are still small in absolute terms. Holding other continuous variables at their means and the dichotomous variables at their modes, if a state agrees entirely with the nondiscretionary outcomes in a proposal, it has a predicted probability of dissenting of only 0.02 (95 per cent confidence interval (95\% CI): 0.01; 0.03). This increases substantially in relative terms, but only marginally in absolute terms, to 0.04 (95\% CI: $0.02 ; 0.06)$ if a state disagrees with non-discretionary outcomes with a value of 0.74 , which is one standard deviation above the average level of disagreement.

The evidence supports the first part of our first hypothesis in that Member States are more likely to dissent from a proposal, the more they disagree with the outcomes in it. However, the evidence does not support the second part of our hypothesis, in which we expected this effect to be stronger for nondiscretionary outcomes. The coefficient associated with the variable 'disagreement with discretionary outcomes' is of a similar size and significance to the first variable, which refers to nondiscretionary outcomes. The difference 
Table 2. Descriptive statistics

\begin{tabular}{|c|c|c|c|c|c|}
\hline & Frequency & Mean & $\begin{array}{l}\text { Standard } \\
\text { deviation }\end{array}$ & Minimum & Maximum \\
\hline \multicolumn{6}{|l|}{ Dependent variable } \\
\hline Signal of dissent & 85 & 0.036 & & 0 & 1 \\
\hline of which voting against & 35 & 0.015 & & 0 & 1 \\
\hline abstaining & 31 & 0.013 & & 0 & 1 \\
\hline $\begin{array}{l}\text { entering a statement without } \\
\text { abstaining or voting against }\end{array}$ & 19 & 0.008 & & 0 & 1 \\
\hline \multicolumn{6}{|l|}{ Explanatory variables } \\
\hline $\begin{array}{l}\text { MS's disagreement with nondiscretionary } \\
\text { outcomes }\end{array}$ & & 0.34 & 0.40 & 0 & 2.71 \\
\hline $\begin{array}{l}\text { MS's disagreement with discretionary } \\
\text { outcomes }\end{array}$ & & 0.11 & 0.25 & 0 & 2.16 \\
\hline $\begin{array}{l}\text { Count of other Member States (above } \\
\text { average trading partners) that dissent }\end{array}$ & & 0.21 & 0.57 & 0 & 6 \\
\hline $\begin{array}{l}\text { Count of other Member States (average } \\
\text { or below average trading partners) } \\
\text { that dissent }\end{array}$ & & 0.59 & 1.14 & 0 & 8 \\
\hline \multicolumn{6}{|l|}{ Control variables } \\
\hline QMV $(=1 ;$ Unanimity $=0)$ & 1,930 & 0.81 & & 0 & 1 \\
\hline Post-2004 (= 1; Pre-2004 = 0) & 1,384 & 0.58 & & 0 & 1 \\
\hline New Member State $(=1 ;$ Old MS = 0) & 614 & 0.26 & & 0 & 1 \\
\hline GDP per capita (in 100,000 s) & & 26.79 & 11.02 & 7.73 & 82.44 \\
\hline
\end{tabular}

Note: 2,384 observations. Units of analysis are Member State-proposal dyads. 118 proposals in total.

between the two coefficients is not significant. So the evidence only partially supports our first hypothesis.

The results of model 1 in Table 3 support the second hypothesis, which posits that Member States are influenced by the behaviour of other Member States, particularly others with which they have close ties. For each additional strong trading partner of state $i$ that dissents, the odds that state $i$ dissents increases by 68 per cent. As above, changes in this variable translate into large relative increases in predicted probabilities of dissent, but the absolute levels are still low. Again, holding other variables at their means or modes, on a proposal on which no other states dissent, any given state has a predicted probability of only 0.02 (95\% CI: $0.01 ; 0.04)$ of dissenting. This increases to 0.04 (95\% CI $0.02 ; 0.05)$ when one other strong trading partner dissents, and to 0.06 (95\% CI: $0.04 ; 0.09)$ when two others dissent.

In line with the second hypothesis, the effect of dissenting behaviour by other states is weaker when those other states are not strong trading partners. The effect of those other states' behaviour is still positive and significant, but is significantly weaker than that of strong trading partners' behaviour. The difference between the two coefficients is statistically significant $(\mathrm{p}<0.01)$.

The magnitude of the effects revealed by these analyses must be considered in the context of the fact that dissent is a rare event that occurs in only 3.6 per cent of all 
Table 3. Factors affecting dissent

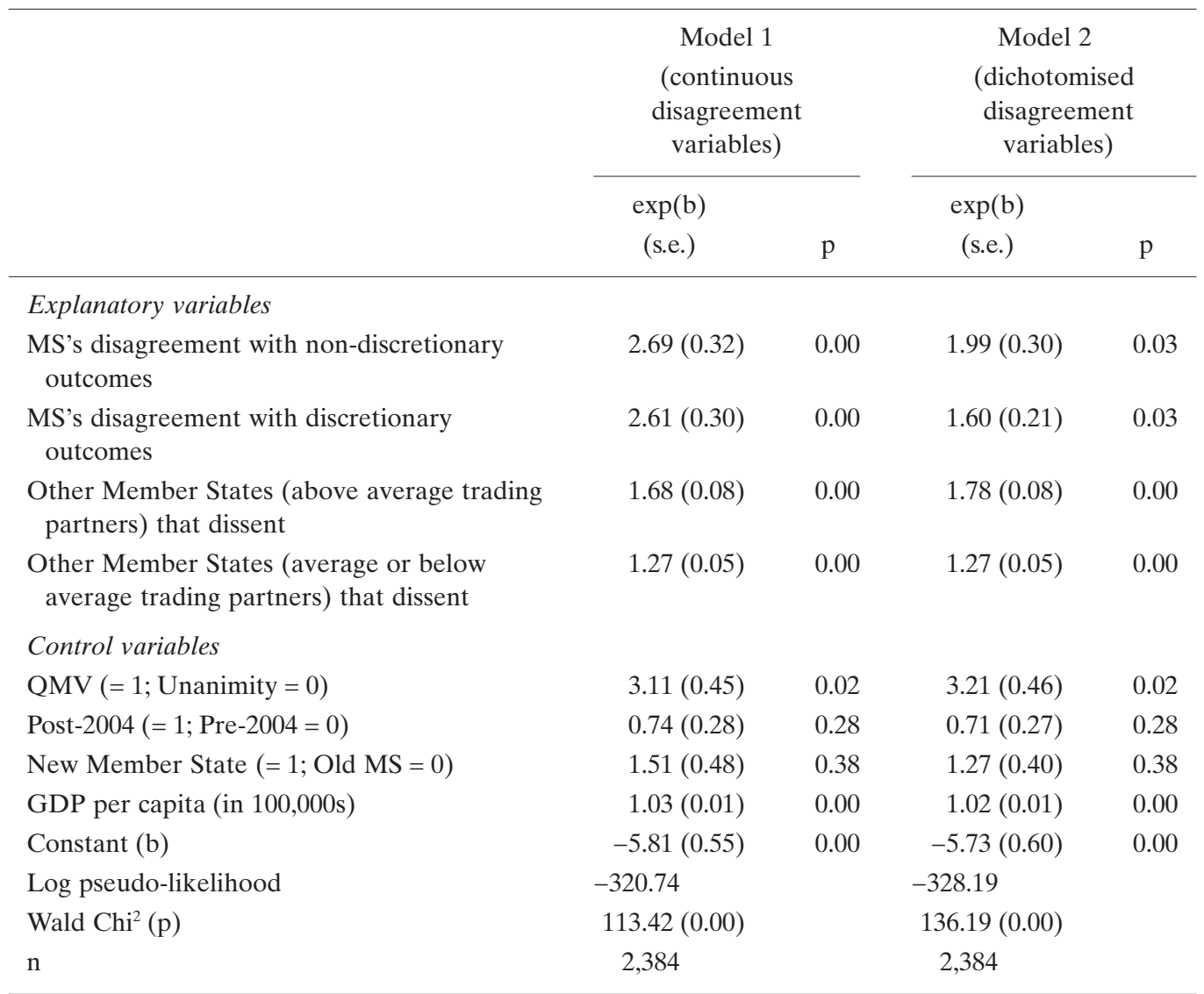

Note: Rare-events logistic regression. Standard errors clustered in 118 legislative proposals.

observations. Taken together, the effects we have identified can amount to substantial variation around this low level. For cases in which a Member State agrees with all of the outcomes, both nondiscretionary and discretionary, and in which no other Member States display dissent, the predicted probability that the Member State in question will dissent is close to zero: 0.01 (95\% CI: $0.01 ; 0.02)$. As above, this assumes the other continuous variables are set at their means and dichotomous variables at their modes. This probability increases to 0.14 (95\% CI: $0.10 ; 0.19)$ for cases in which a Member State disagrees above average with both the discretionary and nondiscretionary outcomes (one standard deviation above the average of each variable) and in which two strong trading partners and two weak trading partners dissent.

These significant effects are also found in the robustness test presented in model 2 in Table 3, in which the first two of our independent variables are dichotomised. Dichotomising the disagreement variables responds to the concern that it may be problematic to compare the distances and salience scores across different issues in different proposals. In addition, the disagreement variables are skewed, with the average values being close to 0 (Table 2). Using dichotomous operationalisations ensures that results are 
not driven by outliers. The robustness test in model 2 gives the same findings. Notably, if a Member State disagrees with nondiscretionary outcomes in a proposal, the odds that it dissents are almost two times greater than if it agrees with those nondiscretionary outcomes. Disagreement with discretionary outcomes has a somewhat weaker effect, although this effect is still significant. The other variables have the same effects as in model 1.

The models also contain control variables that are to some extent relevant to explaining Member States' dissent. We find no significant differences before and after enlargement or between old and new Member States. As would be expected, dissent is significantly more likely when the QMV rule applies, mainly because proposals can still be passed with a few no votes or abstentions. Richer Member States are somewhat more likely to dissent. Although such country characteristics have featured prominently in previous analyses of voting behaviour, we find the theoretical rationale for including them weaker than the variables identified in our explanation.

\section{Conclusions}

We examined the occurrence of dissent at the voting stage in the Council of the EU by quantifying the proportion of cases in which Member States voted against, abstained or entered dissenting statements in the Council minutes without formally voting against or abstaining. Our theory, which emphasises Member States' disagreement with the contents of legislative proposals, led us to focus on a set of proposals that raised at least some controversy after they were introduced. The main descriptive finding is that dissent at the voting stage is a rare event, even in relation to these controversial proposals. Of the 2,384 observations in our analysis, we found evidence of dissent in only 85 cases, which is just 3.6 per cent. This is not much higher than the figures reported in other studies of Member States' behaviour at the voting stage (Mattila 2004, 2008, 2009; Hayes-Renshaw et al. 2006; Hagemann 2008; Hosli et al. 2011; Plechanovová 2011). This is remarkable since these other studies focused on much larger samples of votes that included many proposals that were less contentious than the ones we consider.

We formulated and tested an explanation of dissent that was informed by liberal international relations theory. When Member States dissent, they are attempting to minimise the political costs associated with domestic adjustment costs. By signalling their dissent from domestically unpopular EU laws, national governments can credibly claim they were not responsible for the policy changes brought by these laws. One of our main findings is that dissent is affected by the extent to which Member States disagree with the decision outcomes on which they are voting. Although this inference is a simple one, it is far from a truism, because Member States' strategic considerations, including the preferences of other powerful Member States, may blur the linkage between their policy positions and behaviour.

We find 'voice as a means of avoiding blame' more compelling than 'silence as a means of avoiding blame' (cf. Novak 2013) - at least when explaining variation in dissent. Nonetheless, the overall picture is one of lack of dissent, and in this respect it could be that silence is also used to avoid blame. Future research could examine the conditions under which silence or voice is used to avoid blame. Our explanation suggests that the presence of active 
domestic interests combined with states' disagreement triggers dissent, and this mechanism could be further elaborated and tested in a future study.

We had expected to find a stronger effect of disagreement with nondiscretionary outcomes than with discretionary outcomes, but the evidence did not support our expectation. Discretion has been the focus of much previous research (e.g., Epstein \& O'Halloran 1999; Franchino 2007; Thomson \& Torenvlied 2011). Among the many functions that can be served by discretion, it may increase the quality of public policies by empowering implementation agents that have high levels of policy expertise. It might also be a politically expedient way of resolving controversy, and this appears to be happening more frequently in the enlarged EU (Thomson 2011:272). The absence of a clear effect of discretion in our study may be due to the fact that it is usually limited by controls on implementers - for instance, in the form of rules and conditions that must be met. These controls might mean that domestic adjustment costs are expected even when decision outcomes give some discretion to Member States.

Another part of our explanation posited that the likelihood of dissent by a state is affected by the behaviour of other states, particularly those with which it has strong ties. This corresponds to one of the main propositions of liberal international relations theory namely that states' behaviour is affected by the preferences and behaviour of other states with which they are linked in significant patterns of interdependence (Moravcsik 1997:523). Our evidence shows that a state's decision on whether or not to dissent is, over and above its own policy preferences, affected by the behaviour of other states, particularly by those other states with which it has above average levels of trade. This finding has two related implications. The first is that the strength of ties among Member States varies and that these ties have behavioural effects. Previous research provided evidence of cross-cutting cleavages in the Council, whereby Member States that take similar positions on one legislative proposal often take different positions on other proposals (e.g., Hayes-Renshaw \& Wallace 2006: 250). While our finding on the importance of strong ties among Member States is not inconsistent with the presence of cross-cutting cleavages, it does account for some of the structure we observe among the mesh of issue-specific alignments of Member States. The second implication is that the norm of consensus in the Council is subject to the same mechanisms of violation as other norms. When people see others, particularly their friends, violating a norm, they are more likely to violate the norm themselves. Part of the norm of consensus in the EU is that Member States refrain from dissenting explicitly at the voting stage, even when some of their policy demands have not been met (Heisenberg 2005; Lewis 2008; Novak 2013: 1102). However, when a state's closest partners violate this norm, it is more likely to violate the norm itself.

\section{Acknowledgements}

We thank Mareike Kleine, Christine Reh, Frank Schimmelfennig, the editors and the anonymous reviewers for comments that improved previous versions of this article. We also acknowledge the support received by the Spanish Ministry of Economy and Competitiveness (project CSO2012-35554) for this research. Replication materials are available at the corresponding author's website: www.robertthomson.info. 


\section{Notes}

1. Interview, Brussels, July 2006.

2. Høyland and Wøien Hansen (2014) include the 46 proposals from the DEU dataset that were on the agenda in the years 1999-2000 (the EU-15 period), and on which Member States voted immediately prior to adoption, thereby excluding cases in which the Council voted on a common position, which was subsequently approved by the EP without amendment before becoming law. We include all 118 legislative proposals from the DEU dataset from before and after the 2004 and 2007 enlargements on which Council voting data are available. As well as the different case selection and theoretical propositions, there are numerous other differences between our analyses including: the operationalisation of the disagreement variable; the way indifferent actors are handled; the treatment of statements in the Council minutes; and the statistical model used.

3. Two researchers independently coded each of the 317 issues to identify whether the decision outcome on each issue gave discretion to Member States using the definition given in the text. Their independent coding agreed on 295 of the issues. In a consensus meeting, they reached agreement how to classify the remaining 22 issues.

4. Not all statements made by Member States were instances of dissent. Several were clarifications of Member States' positions without clear indications of disagreement with the outcomes. Some statements were even signals of support for the laws. The dataset contains 142 statements, of which 39 were coded as signals of dissent. Of these 39, 19 were not coupled with dissent in the form of abstaining or voting against, and therefore included in our analysis (Table 2). Two researchers independently coded the 142 statements to identify whether they signalled dissent from the laws adopted. Their independent coding agreed on 130 of these 142 cases, and in a consensus meeting they agreed on how to classify the remaining 12 statements.

5. Rare-events logistic regression adjusts the standard errors to account for the skewed distribution, while the coefficients are the same as in normal logistic regression.

\section{References}

Achen, C.H. (2006). Institutional realism and bargaining models. In R. Thomson et al. (eds), The European Union decides. Cambridge: Cambridge University Press.

Arregui, J. (2008). Shifting policy positions in the European Union. European Journal of Political Research 47(6): 852-875.

Börzel, T.A. (2002). Pace-setting, foot-dragging and fence-sitting: Member State responses to Europeanization. Journal of Common Market Studies 40(2): 193-212.

Bueno de Mesquita, B. (1994). Political forecasting: An expected utility method. In B. Bueno de Mesquita \& F.N. Stokman (eds), European Community decision-making: Models, applications and comparisons. New Haven, CT: Yale University Press.

Epstein, D. \& O'Halloran, S. (1999). Delegating powers: A transaction cost politics approach to policy making under separate powers. Cambridge: Cambridge University Press.

Franchino, F. (2007). The powers of the Union: Delegation in the EU. Cambridge: Cambridge University Press.

Hagemann, S. (2008). Voting, statements and coalition-building in the Council from 1999 to 2006. In D. Naurin \& H. Wallace (eds), Unveiling the Council of the European Union: Games governments play in Brussels. Basingstoke: Palgrave Macmillan.

Hayes-Renshaw, F. \& Wallace, H. (2006). The Council of Ministers, 2nd edn. Basingstoke: Palgrave Macmillan.

Hayes-Renshaw, F., Van Aken, W. \& Wallace, H. (2006). When and why the EU Council of Ministers votes explicitly. Journal of Common Market Studies 44(1): 161-194.

Heisenberg, D. (2005). The institution of consensus in the European Union: Formal vs informal decisionmaking in the Council. European Journal of Political Research 44(1): 65-90.

Héritier, A. (1995). Leaders and laggards in European clean air policy. In B. Unger \& F. Van Waarden (eds), Convergence or diversity: Internationalization and economic policy response. Aldershot: Avebury. 
Hosli, M.O., Mattila, M. \& Uriot, M. (2011). Voting in the Council of the European Union after the 2004 enlargement: A comparison of old and new Member States. Journal of Common Market Studies 49(6): $1249-1270$.

Høyland, B. \& Wøien Hansen, W. (2014). Issue-specific policy positions and voting in the Council. European Union Politics 15(1): 59-81.

Keohane, R.O. \& Nye, J.S. (2011). Power and interdependence, 4th edn. Upper Saddle River, NJ: Pearson Education.

King, G. \& Zeng, L. (2001). Logistic regression in rare events data. Political Analysis 9(2): 137-163.

Lewis, J. (2008). Strategic bargaining, norms and deliberation. In D. Naurin \& H. Wallace (eds), Unveiling the Council of the European Union: Games governments play in Brussels. Basingstoke: Palgrave Macmillan.

Mattila, M. (2004). Contested decisions: Empirical analysis of voting in the European Union Council of Ministers. European Journal of Political Research 43(1): 29-50.

Mattila, M. (2008). Voting and coalitions in the Council after the enlargement. In D. Naurin \& H. Wallace (eds), Unveiling the Council of the European Union: Games governments play in Brussels. Basingstoke: Palgrave Macmillan.

Mattila, M. (2009). Roll call analysis of voting in the European Union Council of Ministers after the 2004 enlargement. European Journal of Political Research 48(6): 840-857.

Moravcsik, A. (1997). Taking preferences seriously: A liberal theory of international politics. International Organization 51(4): 513-553.

Naurin, D. \& Lindahl, R. (2010). Out in the cold? Flexible integration and the political status of Euro opt-outs. European Union Politics 11(4): 485-509.

Novak, S. (2013). The silence of ministers: Consensus and blame avoidance in the Council of the European Union. Journal of Common Market Studies 51(6): 1091-1107.

Plechanovová, B. (2011). The EU Council enlarged: North-south-east or core-periphery? European Union Politics 12(1): 87-106.

Rose, R. \& Davies, P.L. (1994). Inheritance in public policy: Change without choice in Britain. New Haven, CT: Yale University Press.

Thomson, R. (2011). Resolving controversy in the European Union. Cambridge: Cambridge University Press.

Thomson, R. \& Torenvlied, R. (2011). Information, commitment and consensus: A comparison of three perspectives on delegation in the European Union. British Journal of Political Science 41(1): 139-159.

Thomson, R. et al. (eds) (2006). The European Union decides. Cambridge: Cambridge University Press.

Thomson, R. et al. (2012). A new dataset on decision-making in the European Union before and after the 2004 and 2007 enlargements (DEUII). Journal of European Public Policy 19(4): 604-622.

Address for correspondence: Robert Thomson, School of Government and Public Policy, University of Strathclyde, McCance Building, Richmond Street, Glasgow, G1 1XQ, UK. Tel: +44 141548 2733. E-mail: robert.thomson@strath.ac.uk. 